\title{
LAPAROSCOPIC APPENDICECTOMY IN SITUS INVERSUS TOTALIS
}

\author{
M. Bhagavan Naik ${ }^{1}$ K. Sugunakara Rao ${ }^{2}$
}

\section{HOW TO CITE THIS ARTICLE:}

M. Bhagavan Naik, K. Sugunakara Rao. "Laparoscopic Appendicectomy in Situs Inversus Totalis". Journal of Evolution of Medical and Dental Sciences 2015; Vol. 4, Issue 29, April 09; Page: 5064-5067,

DOI: $10.14260 /$ jemds/2015/738

\begin{abstract}
Situs inversus totalis (SIT) is an uncommon anomaly characterized by transposition of organs to the opposite side of the body in a mirror image of normal. Appendicitis in situs inversus patients can create diagnostic dilemma due to incongruous symptoms and signs because of the contra lateral disposition of the viscera. This may causes delay in proper diagnosis and treatment and may lead to incisions in inappropriate sites. Diagnostic laparoscopy excludes other causes of lower abdominal pain as well as it can localize the exact position of appendix. We present the case of left sided appendicitis and situs inversus totalis, who presented with pain in left iliac fossa and on examination there was rebound tenderness in left iliac fossa. Ultrasound abdomen revealed left sided appendicitis with situs inversus totalis. Laparoscopic appendicectomy was done successfully. We have done review of left sided appendicitis cases in pub med and and some of the characteristics are summarized in this article.
\end{abstract}

KEYWORDS: Laparoscopic appendicectomy, situs inversus totalis, left sided appendicitis.

INTRODUCTION: Situs inversus totalis (SIT) is an uncommon anomaly characterized by transposition of Organs to the opposite side of the body in a mirror image of normal.[1] It occurs in 1: 20,000 of the general population. Situs inversus totalis complicates diagnosis and management of acute abdominal pain. Acute appendicitis in these patients may present with confusing symptoms and signs because of abnormal position of appendix. About $50 \%$ of patients with left-sided appendicitis, for example, have pain on the right side. ${ }^{[2]}$ We present the case of a boy with left sided appendicitis and situs inversus totalis, who was unaware of this condition, presented with pain in left iliac fossa and hypogastrium and rebound tenderness in left iliac fossa. Ultrasound abdomen revealed left sided appendicitis with situs inversus totalis. This case is particularly interesting because of the rarity of this association and the diagnostic difficulties that arise because of unusual, confusing clinical findings.

CASE REPORT: A 16 years male patient came to emergency department with pain in left iliac fossa and hypo gastrium, which started previous night. Patient also had nausea and one episode of vomiting. Our physical examination was notable only for rebound tenderness in left iliac fossa. Temperature is 38 degrees centigrade.

Laboratory findings: Hb12 gm\%, total count 14,000/cu. mm, R.B.S. 96mg\%, serum creatinine$1.2 \mathrm{mg} \%$. Based on these clinical findings, we considered right and left sided appendicitis, diverticulitis, and renal colic were considered in differential diagnosis.

Chest $\mathrm{x}$-ray[Fig. 1] revealed dextrocardia and fundic gas shadow on right side. Ultra sound abdomen showed situs inversus and probe tenderness in left iliac fossa. A diagnostic laparoscopy was performed for a presumed diagnosis of acute appendicitis with situs inversus. T. V. monitor was kept on left side of the patient. Surgeon as well as camera assistant was standing on right side of the 
patient. Initial diagnostic laparoscopy, through $10 \mathrm{~mm}$ umbilical camera port, has confirmed the ultrasonographic finding of visceral situs inversus totalis.[Fig. 2] At the same time an inflamed appendix was seen in left iliac fossa.[Fig. 3] Two other $5 \mathrm{~mm}$ ports were placed, one in suprapubic region, another one in right iliac fossa. Appendix was holded with grasper through the port placed in right iliac fossa. Meso appendix was cauterized with bipolar cautery and base of the appendix was ligated with loop ligature and divided. Specimen was retrieved through $10 \mathrm{~mm}$ port. Operative time was 30 minutes and post-operative period was UN eventful.

DISCUSSION: Left sided appendicitis occurs in two conditions, situs inversus totalis and mid gut malrotation. Situs inversus results from a rotation in the opposite direction of the viscera during the development of the embryo. Due to the contra lateral disposition of the viscera, the diagnosis and surgical approach of these patients may be more difficult than that of normal patients. About $40 \%$ $50 \%$ patients of acute appendicitis with left sided appendix present with pain in right iliac fossa. This phenomenon suggests that the central nervous system may not share in the general transposition.[3] This diagnostic dilemma causes delay in proper diagnosis and treatment. These incongruous symptoms and signs in this condition may lead to incisions in inappropriate sites which have been documented in greater than $40 \%$ of such cases. A detailed clinical history, physical examination and proper radiological investigations are useful in obtaining accurate diagnosis. Ultrasound abdomen is helpful for diagnosis in most of the cases. However, CT scan abdomen is more accurate in localization of offending organ.

When there is a doubt regarding diagnosis, laparoscopy should be done as early as possible to prevent further complications of appendicitis like gangrene and perforation. Diagnostic laparoscopy can localize the exact position of appendix so that inappropriate incisions can be prevented, even if open appedicectomy is planned. Furthermore, diagnostic laparoscopy through umbilical port has an invaluable role in these cases, as this allows other two ports to be strategically placed and laparoscopic appendicectomy can be done without any technical difficulties. ${ }^{[4]}$

Some authors suggest that appendicectomy should be done even prophylactically, if laparoscopy is done for other cause. This may prevent future problems in diagnosis and treatment of appendicitis in these patients.[2][5][6]

The pub med search was done.[4][5][6][7][8][9][10] and it was noted that Akbulut $\mathrm{S}$ et al[8] have published a review of 95 Left-sided appendicitis cases and a case report and recently Borgaonkar VD et al[7] have published a case report of Laparoscopic cholecystectomy and appendicectomy in situs inversus totalis. Total 98 patients were undergone surgery for left sided appendicitis including this case. After reviewing these articles some of the clinical characteristics of these cases are summarized below [Table 1], [Table 2], [Table 3], [Table 4].

\begin{tabular}{|c|c|}
\hline Situs inversus totalis & 69 \\
\hline Malrotation of mid gut & 23 \\
\hline Others & 6 \\
\hline
\end{tabular}




\begin{tabular}{|c|c|}
\hline Left side & 62 \\
\hline Right side & 14 \\
\hline B/L lower quadrant & 7 \\
\hline Other areas & 8 \\
\hline
\end{tabular}

\section{Table 2: Localization of pain}

\begin{tabular}{|c|c|}
\hline Pre-operative & 52 \\
\hline Intra operative & 19 \\
\hline Known & 14 \\
\hline
\end{tabular}

Table 3: Time of diagnosis

\begin{tabular}{|c|c|}
\hline Laparoscopic appendicectomy & 10 \\
\hline open appendicectomy & 88 \\
\hline \multicolumn{2}{|c|}{ Table 4: Technique of surgery } \\
\hline
\end{tabular}

In conclusion, the association of appendicitis and situs inversus can create diagnostic dilemma because of the contra lateral disposition of the viscera. Familiarity of this association makes a timely and accurate diagnosis that will prevent complications and incisions at inappropriate sites. However, ultrasound abdomen and C. T. scan are necessary for accurate diagnosis. Laparoscopic approach is ideal for diagnosis as well as management of pain abdomen in situs inversus totalis.

\section{REFERENCES:}

1. Mauro Neiva Fernandes, Ivan Nazareno Campos Neiva, Francisco de Assis Camacho, Lucas Crociati Meguins, Marcelo Neiva Fernandes, and Emília Maíra Crociati Meguins. Three-Port Laparoscopic Cholecystectomy in a Brazilian Amazon Woman with Situs Inversus Totalis: Surgical Approach. Case Rep Gastroenterol 2008; 2: 170-174.

2. Jonathan Y. Song, Nasir Rana, Carlos A. Rotman. Laparoscopic Appendectomy in a Female Patient with Situs Inversus: Case Report and Literature Review. JSLS 2004; 8: 175-177.

3. Norman Oneil Machado, Pradeep Chopra. Laparoscopic Cholecystectomy in a Patient with Situs Inversus Totalis: Feasibility and Technical Difficulties. JSLS 2006; 10: 386-391.

4. Palanivelu C, Rangarajan M, John SJ, Senthilkumar R, Madhankumar MV.

Laparoscopic appendectomy for appendicitis in uncommon situations: the advantages of a tailored approach. Singapore Med J 2007; 48: 737-40.

5. Golash V, Willson PD. Early laparoscopy as a routine procedure in the management of acute abdominal pain: a review of 1,320 patients. Surg Endosc 2005; 19: 882-5.

6. Golash V. Laparoscopic management of acute appendicitis in situs inversus. J Minim Access Surg 2006; 2: 220-1.

7. Borgaonkar VD, Deshpande SS, Kulkarni VV. Laparoscopic cholecystecto my and appendicectomy in situs inversus totalis: A case report and review of literature. J Minim Access Surg 2011; 7: 242-5. 


\section{CASE REPORT}

8. Akbulut S, Ulku A, Senol A, Tas M, Yagmur Y. Left-sided appendicitis: review of 95 published cases and a case report. World J Gastroenterol 2010; 16: 5598-602.

9. Djohan RS, Rodriguez HE, Wiesman IM, Unti JA, Podbielski FJ. Laparoscopic cholecystectomy and appendicectomy in situs inversus totalis. JSLS 2000; 4: 251-4.

10. Van Steensel CJ, Wereldsma JC. Acute appendicitis in complete situs inversus. Neth J Surg 1985; 37: 117-8.

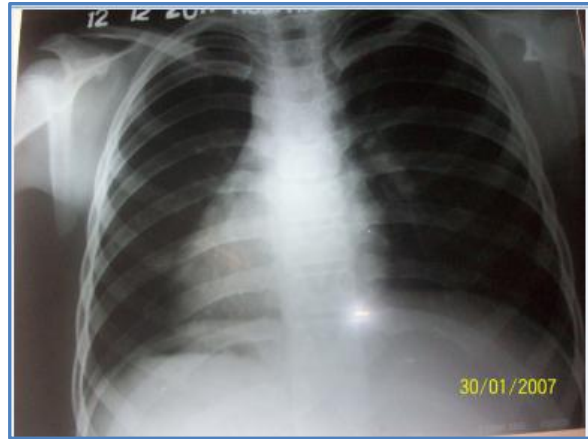

Fig. 1: $x$-ray showing Dextro Cardia

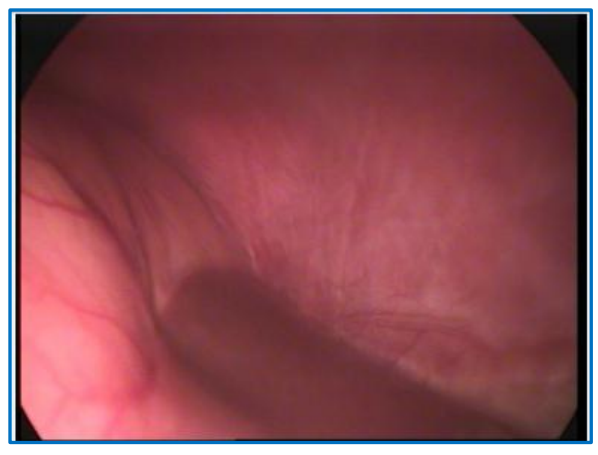

Fig. 2: Greater Curvature of Stomach on right side

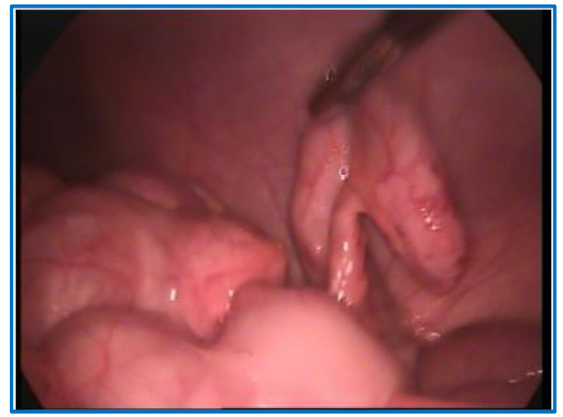

Fig. 3: Inflammed appendix in left iliac Fossa

\section{AUTHORS:}

1. M. Bhagavan Naik

2. K. Sugunakara Rao

\section{PARTICULARS OF CONTRIBUTORS:}

1. Associate Professor, Department of General Surgery, Andhra Medical College.

2. Assistant Professor, Department of General Surgery, Andhra Medical College.

FINANCIAL OR OTHER

COMPETING INTERESTS: None

\author{
NAME ADDRESS EMAIL ID OF THE \\ CORRESPONDING AUTHOR: \\ Dr. K. Sugunakara Rao, \\ Assistant Professor, \\ Department of General Surgery, \\ Andhra Medical College, \\ Visakhapatnam. \\ E-mail: suggukodi@yahoo.co.in
}

Date of Submission: 25/03/2015.

Date of Peer Review: 26/03/2015.

Date of Acceptance: 30/03/2015.

Date of Publishing: 09/04/2015. 